\title{
Glucose tolerance and insulin resistance in Indian children: relationship to infant feeding pattern
}

\author{
S. R. Veena • G. V. Krishnaveni • A. K. Wills • J. C. Hill • \\ S. C. Karat • C. H. D. Fall
}

Received: 4 April 2011 / Accepted: 20 June 2011 /Published online: 20 July 2011

(C) Springer-Verlag 2011

\begin{abstract}
Aims/hypothesis Our objective was to examine whether longer duration of breast-feeding and later introduction of complementary foods are associated with lower glucose concentrations and insulin resistance (IR-HOMA) in Indian children.

Methods Breast-feeding duration (six categories from $<3$ to $\geq 18$ months) and age at introduction of complementary foods (four categories from $<4$ to $\geq 6$ months) were recorded at 1,2 and 3 year follow-up of 568 children from a birth cohort in Mysore, India. At 5 and 9.5 years of age, 518 children were assessed for glucose tolerance and IR-HOMA.

Results All the children were initially breast-fed; $90 \%$ were breast-fed for $\geq 6$ months and $56.7 \%$ started complementary foods at or before the age of 4 months. Each category increase in breast-feeding duration was associated with lower fasting insulin concentration $(\beta=-0.05 \mathrm{pmol} / 1[95 \%$ CI $-0.10,-0.004] ; p=0.03)$ and IR-HOMA $(\beta=-0.05$ $[95 \% \mathrm{CI}-0.10,-0.001] ; p=0.046)$ at 5 years, adjusted for the child's sex, age, current BMI, socioeconomic status, parent's education, rural/urban residence, birthweight and maternal gestational diabetes status. Longer duration of
\end{abstract}

Electronic supplementary material The online version of this article (doi:10.1007/s00125-011-2254-x) contains peer-reviewed but unedited supplementary material, which is available to authorised users.

S. R. Veena $(\bowtie) \cdot$ G. V. Krishnaveni $\cdot$ S. C. Karat Epidemiology Research Unit, Holdsworth Memorial Hospital, P.O. Box 38, Mandi Mohalla,

Mysore 570021, India

e-mail: veenasr@gmail.com

A. K. Wills · J. C. Hill • C. H. D. Fall

MRC Lifecourse Epidemiology Unit,

Southampton General Hospital,

Southampton, UK breastfeeding was associated with higher 120-min glucose concentration at 5 years $(\beta=0.08 \mathrm{mmol} / 1$ [95\% CI 0.001 , $0.15 ; p=0.03]$ ) but lower 120 -min glucose concentration at 9.5 years $(\beta=-0.09[95 \% \mathrm{CI}-0.16,-0.03] ; p=0.006)$. Age at starting complementary foods was unrelated to the children's glucose tolerance and IR-HOMA.

Conclusions/interpretation Within this cohort, in which prolonged breast-feeding was the norm, there was evidence of a protective effect of longer duration of breast-feeding against glucose intolerance at 9.5 years. At 5 years longer duration of breast-feeding was associated with lower IR-HOMA.

Keywords Breast-feeding · Children · Complementary foods $\cdot$ Glucose tolerance $\cdot$ India $\cdot$ Insulin resistance
Abbreviations
GDM Gestational diabetes mellitus
IR-HOMA Insulin resistance HOMA

\section{Introduction}

Children and adults who were breast-fed rather than bottlefed, and breast-fed for a longer duration during infancy have lower rates of type 2 diabetes and lower insulin resistance (IR-HOMA) [1, 2]. It has been suggested that differences between breast-fed and bottle-fed babies in the nutrient quality of the milk, patterns of infant weight gain, or in learned feeding behaviour influence later diabetes risk [1]. Few studies have examined diabetes risk in relation to the age at starting complementary foods in infancy.

In the Mysore Parthenon birth cohort study [3], data collected on infant feeding practices, and subsequent 
measurements of plasma glucose and insulin concentrations in the children enabled us to examine whether longer duration of breast-feeding and later introduction of complementary foods are associated with lower glucose concentrations and IR-HOMA in Indian children, and whether these associations change with age.

\section{Methods}

As described previously [3], 830 pregnant women underwent an OGTT at $30 \pm 2$ weeks of gestation (49 had gestational diabetes [GDM]). Of these, 663 delivered live normal babies at the Holdsworth Memorial Hospital, Mysore. The children had detailed anthropometry at birth, annually until the age of 5 years and every 6 months thereafter.

Infant feeding data were collected at 1, 2 and 3 years of age by asking mothers the following questions: How was the baby fed from birth (breast, bottle, breast+bottle or other)? If breast-fed, was the baby still being breast-fed? If not, at what age (months) was breast-feeding stopped? At 1 year, mothers were asked the age in months at which their baby started taking solid foods regularly.

Five hundred and eighty-five children $(93 \%$ of survivors) were studied at 5 years and $539(86 \%)$ at 9.5 years. Weight (Salter, Tonbridge, UK) and height (Microtoise, CMS Instruments, London, UK) were measured using standardised methods. After an overnight fast, blood
Table 1 General characteristics of the study cohort $p$ values for the differences between boys and girls derived using Student's $t$ test or $\chi^{2}$ test

${ }^{a}$ Log-transformed variable; values are median and interquartile range

\begin{tabular}{|c|c|c|c|}
\hline Infant feeding & Boys $(n=246)$ & Girls $(n=272)$ & $p$ value \\
\hline \multicolumn{4}{|c|}{ Breast-feeding duration categories, $n(\%)$} \\
\hline$<3$ months & $7(2.9)$ & $7(2.6)$ & \multirow[t]{6}{*}{0.6} \\
\hline $3-5$ months & $23(9.4)$ & $19(7.0)$ & \\
\hline $6-8$ months & $26(10.6)$ & $23(8.5)$ & \\
\hline 9-11 months & $34(13.8)$ & $45(16.5)$ & \\
\hline $12-17$ months & $105(42.7)$ & $131(48.2)$ & \\
\hline$\geq 18$ months & $51(20.7)$ & $47(17.3)$ & \\
\hline \multicolumn{4}{|l|}{ Age at starting regular solids, $n(\%)$} \\
\hline$<4$ months & $43(18.7)$ & $51(20.2)$ & \multirow[t]{4}{*}{0.5} \\
\hline 4 months & $81(35.2)$ & $99(39.1)$ & \\
\hline 5 months & $70(30.4)$ & $61(24.1)$ & \\
\hline$\geq 6$ months & $36(15.7)$ & $42(16.6)$ & \\
\hline \multicolumn{4}{|c|}{ Child characteristics at 5 years (mean $\pm \mathrm{SD}$ ) } \\
\hline Age (years) & $5.0 \pm 0.04$ & $5.0 \pm 0.03$ & 0.09 \\
\hline Height (cm) & $106.3 \pm 4.3$ & $104.9 \pm 4.3$ & 0.0004 \\
\hline BMI $\left(\mathrm{kg} / \mathrm{m}^{2}\right)$ & $13.6 \pm 1.0$ & $13.5 \pm 1.2$ & 0.6 \\
\hline Fasting glucose $(\mathrm{mmol} / \mathrm{l})$ & $4.9 \pm 0.5$ & $4.8 \pm 0.3$ & 0.3 \\
\hline $30 \mathrm{~min}$ glucose $(\mathrm{mmol} / \mathrm{l})$ & $7.2 \pm 1.5$ & $7.4 \pm 1.3$ & 0.1 \\
\hline $120 \mathrm{~min}$ glucose $(\mathrm{mmol} / \mathrm{l})$ & $5.9 \pm 1.0$ & $5.9 \pm 0.9$ & 0.5 \\
\hline Fasting insulin $(\mathrm{pmol} / \mathrm{l})^{\mathrm{a}}$ & $18.6(11.4,28.6)$ & $22.7(15.0,22.7)$ & $<0.0001$ \\
\hline $30 \min$ insulin $(\mathrm{pmol} / \mathrm{l})^{\mathrm{a}}$ & $120.1(75.8,211.1)$ & $168.4(108.0,242.0)$ & 0.0006 \\
\hline 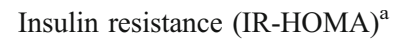 & $0.6(0.4,1.0)$ & $0.8(0.5,1.2)$ & 0.0001 \\
\hline Insulin increment $\mathrm{a}^{\mathrm{a}}$ & $14.3(9.0,24.7)$ & $19.5(12.8,27.0)$ & 0.02 \\
\hline \multicolumn{4}{|c|}{ Child characteristics at 9.5 years $($ mean \pm SD) } \\
\hline Age (years) & $9.4 \pm 0.1$ & $9.4 \pm 0.1$ & 0.3 \\
\hline Height $(\mathrm{cm})$ & $131.3 \pm 5.5$ & $130.3 \pm 5.9$ & 0.07 \\
\hline BMI $\left(\mathrm{kg} / \mathrm{m}^{2}\right)$ & $14.6 \pm 1.8$ & $14.7 \pm 2.0$ & 0.9 \\
\hline Fasting glucose (mmol/l) & $4.7 \pm 0.4$ & $4.7 \pm 0.4$ & 0.1 \\
\hline 30 min glucose $(\mathrm{mmol} / \mathrm{l})$ & $6.7 \pm 1.3$ & $6.9 \pm 1.2$ & 0.1 \\
\hline 120 min glucose $(\mathrm{mmol} / \mathrm{l})$ & $5.0 \pm 1.0$ & $5.2 \pm 0.8$ & 0.067 \\
\hline Fasting insulin $(\mathrm{pmol} / \mathrm{l})^{\mathrm{a}}$ & $19.2(12.0,28.8)$ & $26.4(18.6,36.0)$ & $<0.0001$ \\
\hline $30 \min$ insulin $(\mathrm{pmol} / \mathrm{l})^{\mathrm{a}}$ & $208.2(124.8,342.0)$ & $270.0(166.8,408.0)$ & $<0.0001$ \\
\hline Insulin resistance (IR-HOMA) ${ }^{\mathrm{a}}$ & $0.7(0.4,1.0)$ & $0.9(0.6,1.3)$ & $<0.0001$ \\
\hline Insulin increment $\mathrm{t}^{\mathrm{a}}$ & $26.5(16.8,45.5)$ & $35.3(21.6,49.7)$ & 0.005 \\
\hline
\end{tabular}


There were no significant associations between breastfeeding duration and parental education or socioeconomic status.

At 5 years, 120-min glucose concentration increased, whereas fasting insulin concentration and IR-HOMA decreased with increasing duration of breast-feeding, independent of potential confounders (Table 2). The 30min insulin concentration tended to fall with increasing breast-feeding duration, although this was non-significant. At 9.5 years, 120 -min glucose concentration decreased with increasing duration of breast-feeding. IR-HOMA was unrelated to breast-feeding duration (Table 2).

Breast-feeding duration correlated with the age at starting complementary foods (Spearman $r=0.1 ; p=0.02$ ). Earlier introduction of complementary foods was associated with higher BMI at 9.5 years $(p=0.04)$ and maternal education $(p=0.051)$. There were no significant associations, at either 5 or 9.5 years, of age at starting complementary foods with glucose tolerance or IRHOMA (Table 2).

The findings were unchanged when we re-analysed our data using breast-feeding duration or age at starting complementary foods as continuous or normalised variables, or if the categories were changed; when breast-feeding duration and age at starting complementary foods were included simultaneously in the regression; when preterm $(n=34)$ and offspring of GDM mothers $(n=33)$ were excluded and when weight at 1 year was included with all the other confounders (data not shown). The associations were similar in boys and girls and there were no non-linear associations.

\section{Discussion}

We have shown in a cohort of Indian children, among whom prolonged breast-feeding was the norm across all socioeconomic groups, that longer breast-feeding duration was associated with lower fasting insulin concentrations and IR-HOMA at 5 years, but not at 9.5 years. Longer breast-feeding duration was associated with higher 120-min glucose concentration at 5 years, but lower 120-min glucose at 9.5 years. These associations were independent of all potential confounding factors measured. There were no significant associations of age at starting complementary foods with glucose/insulin concentrations.

A strength of the study was that breast-feeding data were obtained prospectively. Limitations were a lack of information on the exclusivity and frequency of breast-feeding, the nutritional quality of the breast milk or the type of milk used after stopping breast-feeding, the type and nutritional quality of complementary foods, and current diet and physical activity.
Longer breast-feeding duration was associated with lower fasting insulin concentrations and IR-HOMA at 5 but not 9.5 years, suggesting that this association changes with age. There are no previous reports of serial measures of insulin in relation to breast-feeding. A meta-analysis of studies in developed countries (four in adults and two in children) [2] showed no differences in fasting insulin concentrations among those who were breast-fed or not. Similarly, two studies in adults $[1,2]$ and three in children $[1,2,6]$ reported no association of exclusive breast-feeding and/or its duration with IR-HOMA [1, 2]. However, a recent study reported an inverse association between breastfeeding duration and IR-HOMA in adult men [7].

A notable finding in our study was that the association between breast-feeding duration and 120-min glucose concentrations changed in direction between 5 and 9.5 years. Children who stopped breast-feeding earlier had lower 120-min glucose concentrations at 5 years, but higher 120 -min glucose at 9.5 years. In addition to having higher fasting insulin concentrations, they tended to have higher 30-min insulin concentrations. This may be analogous to the phenomenon observed in animal studies, in which offspring of rat dams exposed to a nutritional insult (highcarbohydrate or low-protein diets) during pregnancy have fewer and smaller pancreatic islets, long-term changes in the structure and function of insulin-sensitive tissues (liver, adipocytes and muscle) and reduced insulin signalling protein production. These changes are associated with hyperinsulinaemia, enhanced glucose tolerance or reactive hypoglycaemia in the young animal and to glucose intolerance later [8]. Such a progression has not previously been reported in humans, although few have serial data like ours through childhood.

Consistent with findings from many studies including a meta-analysis, mainly from high-income countries, our data at 9.5 years suggest that longer breast-feeding is associated with better glucose tolerance, and possibly lower diabetes risk, in later life. Whether these associations are causal is unknown, but animal studies have demonstrated that the high long-chain polyunsaturated fatty acid content of breast milk may suppress proinflammatory cytokine production, regulate neurotransmitter function, enhance insulin receptor numbers in the brain and other tissues, and decrease IRHOMA [9]. Whether these changes could persist up to the age of 5 or 9.5 years is unknown. Breast-fed babies are thought to develop better satiety sensing than formula-fed babies and gain less weight during infancy [1], both of which may protect against later obesity and thus diabetes.

Few studies have examined the association of age at starting complementary foods with later IR-HOMA and glucose tolerance. Consistent with our findings, a recent study found no association among young adults [10]. As growth in infancy influences later health, timely introduction 
and nutritional quality of complementary foods are important for promoting optimal growth and lifelong health.

To conclude, in this cohort of healthy Indian children, there was evidence of a possible protective effect of longer breast-feeding duration against later diabetes, suggesting that promoting WHO guidelines (exclusive breast-feeding for 6 months, introduction of nutritious complementary foods from 6 months and continued breast-feeding up to 2 years) [11] may contribute to reducing the escalating incidence of diabetes in developing countries. This improved glucose tolerance may be associated with a transient period of lower IR-HOMA and higher glucose concentrations in early childhood.

Acknowledgements We are grateful to the families who participated in the study. We acknowledge the contribution made to the study by the research team (Epidemiology Research Unit, HMH, Mysore), and SNEHA-India for its support. The study was funded by the Parthenon Trust, Switzerland, the Wellcome Trust, UK, and the Medical Research Council, UK.

Contribution statement SRV: conception and design, analysis and interpretation of data, drafting the article and approval of final version. GVK, JCH, SCK: conception and design, revising the manuscript critically for intellectual content and approval of final version. AKW: analysis and interpretation of data, revising the manuscript critically for intellectual content and approval of final version. CHDF: conception and design, interpretation of data and revising the manuscript critically for intellectual content and approval of final version.

Duality of interest The authors declare that there is no duality of interest associated with this manuscript.

\section{References}

1. Horta BL, Bahl R, Martinés JC, Victora CG (2007) Evidence on the long-term effects of breastfeeding: systematic reviews and meta-analyses. WHO, Geneva

2. Owen CG, Martin RM, Whincup PH, Smith GD, Cook DG (2006) Does breastfeeding influence risk of type 2 diabetes in later life? A quantitative analysis of published evidence. Am J Clin Nutr 84:1043-1054

3. Krishnaveni GV, Hill JC, Leary SD et al (2005) Anthropometry, glucose tolerance, and insulin concentrations in Indian children: relationships to maternal glucose and insulin concentrations during pregnancy. Diabetes Care 28:2919-2925

4. Matthews DR, Hosker JP, Rudenski AS, Naylor BA, Treacher DF, Turner RC (1985) Homeostasis model assessment: insulin resistance and $\beta$-cell function from fasting glucose and insulin concentrations in man. Diabetologia 28:412-419

5. Wareham NJ, Phillips DIW, Byrne CD, Hales CN (1995) The 30 minute insulin incremental response in an oral glucose tolerance test as a measure of insulin secretion. Diabet Med 12:684-688

6. Corvalán C, Kain J, Weisstaub G, Uauy R (2009) Impact of growth patterns and early diet on obesity and cardiovascular risk factors in young children from developing countries. Proc Nutr Soc 68:327-337

7. Pearce MS, Unwin NC, Parker L, Alberti KG (2006) Life course determinants of insulin secretion and sensitivity at age 50 years: the Newcastle thousand families study. Diabetes Metab Res Rev 22:118-125

8. Jones RH, Ozanne SE (2007) Intra-uterine origins of type 2 diabetes. Arch Physiol Biochem 113:25-29

9. Lombardo YB, Chicco AG (2006) Effects of dietary polyunsaturated n-3 fatty acids on dyslipidemia and insulin resistance in rodents and humans. J Nutr Biochem 17:1-13

10. Fall CH, Borja JB, Osmond C et al (2011) Infant-feeding patterns and cardiovascular risk factors in young adulthood: data from five cohorts in low- and middle-income countries. Int J Epidemiol 40:47-62

11. World Health Organization, UNICEF (2003) Global strategy for infant and young child feeding. WHO, Geneva 